Article

\title{
Smartphone Application for Determining the Segregation Index of Lightweight Aggregate Concrete
}

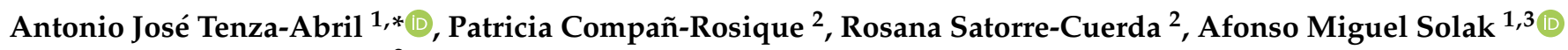 \\ and Daniel Gavotti Freschi ${ }^{2}$ \\ 1 Department of Civil Engineering, University of Alicante, 03690 San Vicente del Raspeig, Spain; \\ afonsosolak@gmail.com \\ 2 Department of Computer Science \& Artificial Intelligence, University of Alicante, \\ 03690 San Vicente del Raspeig, Spain; patricia.company@ua.es (P.C.-R.); rosana.satorre@ua.es (R.S.-C.); \\ danielgavottifreschi@gmail.com (D.G.F.) \\ 3 CYPE Ingenieros S.A., 03003 Alicante, Spain \\ * Correspondence: ajt.abril@ua.es
}

Citation: Tenza-Abril, A.J.; Compañ-Rosique, P.; Satorre-Cuerda, R.; Solak, A.M.; Gavotti Freschi, D. Smartphone Application for Determining the Segregation Index of Lightweight Aggregate Concrete. Sustainability 2021, 13, 12564. https://doi.org/10.3390/su132212564

Academic Editors: José

Ignacio Alvarez, Yolanda Villacampa, Francisco José Navarro-Gonzalez, Isabel López and José Ignacio Pagán

Received: 28 September 2021 Accepted: 9 November 2021 Published: 14 November 2021

Publisher's Note: MDPI stays neutral with regard to jurisdictional claims in published maps and institutional affiliations.

Copyright: (c) 2021 by the authors. Licensee MDPI, Basel, Switzerland. This article is an open access article distributed under the terms and conditions of the Creative Commons Attribution (CC BY) license (https:/ / creativecommons.org/licenses/by/ $4.0 /)$.

\begin{abstract}
Due to the low density of the aggregates and the longer mixing times, lightweight aggregate concrete (LWAC) is susceptible to segregation of the aggregates. Several studies have proposed different methods to estimate the segregation of concrete because segregation affects strength and durability in structures. Image analysis techniques have become very popular for quickly analysing different materials and, together with the widespread use of mobile applications, can make it much easier for engineers to obtain parameters that identify concrete segregation. The aim of this work was the development of a mobile application to photograph the section of a concrete specimen and indicate the segregation values. A simple, fast, and effective application was implemented, and the results were validated with other previously published results, which can facilitate the task of engineers and researchers to determine the segregation of concrete.
\end{abstract}

Keywords: mobile application; segregation; lightweight concrete; image analysis; resolution

\section{Introduction}

Concrete is one of the most important building materials throughout history; it has been used for more than two thousand years, and it is still used today because of its versatility. Concrete can be produced with a large variety of compositions, finishes, and performance characteristics to meet a wide range of needs. Lightweight aggregate concrete (LWAC) incorporates lightweight aggregates (LWA) into its mix and allows flexibility in the design, providing many advantages. There has been a rapidly growing demand for LWAC owing to its low weight, which reduces dead loads sustained by structural elements, reducing costs of foundation and seismic loads [1] and improving permeability [2]. Additionally, LWAC has favourable effects on the thermal properties due to its density, which provides better thermal insulation and fire resistance [3,4]. LWAC, due to its good thermal properties [5], is a real alternative to conventional concretes because it reduces the bridging effects and contributes to reducing energy needs [6]. LWAC contributes to sustainable development by optimizing structural efficiency, improving durability, and extending concrete's service life.

To achieve the designed strength and durability requirements, fresh concrete has to be compacted in a proper way [7]. Assuring a good mixture consistency is difficult because the conditions of the concrete materials are constantly changing. In LWAC this is more acute because the difference of the density between the LWA and the rest of the components [8]. Due to the low density of the aggregates and the longer mixing times, LWAC is susceptible to segregation of the aggregates [9]. Segregation in LWAC is the separation of cement paste and LWA from each other during handling and placement. Segregation is more acute 
due to over-vibration or compaction of LWA [10,11], in which cement paste comes to the top and LWA floats to the top in LWAC or settles at the bottom when the aggregates are denser than the cement paste. Segregation of concrete affects the strength $[10,12]$ and the durability of structures $[13,14]$.

Several studies have proposed different methods to estimate the segregation of concrete based on mixture design and vibratory energy [15] or by evaluating the use of artificial neural networks to predict the compressive strength of segregated LWAC using ultrasonic pulse velocity [16], which is done because visual inspection is insufficient.

Image analysis techniques have become very popular for quickly analysing the behaviour of cement-based materials. There is a large production of scientific literature in the field of image analysis methods for concrete. The methods of image analysis have been utilized for many applications because they provide many advantages. For example, crack detection is used for structural health monitoring $[17,18]$, computer vision is used to assess fires [19], bughole concrete detection is used [20], and the mixing concrete evolution is monitored [21]. There are several methods for measuring or identifying the segregation in hardened LWAC and conventional concretes [22-25], and the most extended method is using image-processing-based techniques [25-27]; furthermore, determining densities of different sections of a concrete specimen is also used [28] for evaluating the segregation [29]. The main goal of these techniques is to confirm well-graded, homogenously distributed, and randomly oriented coarse aggregate to improve the concrete mechanical and durability properties.

Today, the advance of mobile technologies has changed our daily life. Incorporating image processing capabilities on mobile devices opens new opportunities in different application contexts [30]. The high computational complexity of some image processing algorithms, the long processing time, and the energy consumption limit the wide practice in mobile applications [31].

The main objective of this work was to develop an application for smartphones based on Android operating systems that facilitate the determination of several segregation indexes through the image analysis technique. The smartphone application implemented used the camera installed on the smartphone for facilitating the analysis in hardened samples of LWAC with no expert human resources.

\section{Materials and Methods}

To develop the smartphone application, the methodology followed is summarized in Figure 1.

1. Develop the mobile application programming the interface and usability implementing the methodology described in [32,33].

2. Validate the results using the photographs and values of the segregation index according to the methodology proposed by Ke et al. [28] and the methodology proposed by Solak et al. [26], comparing the values obtained using Image J software and the mobile application developed.

3. Conclusions about the mobile application developed.

Compare values previously published with the smartphone application
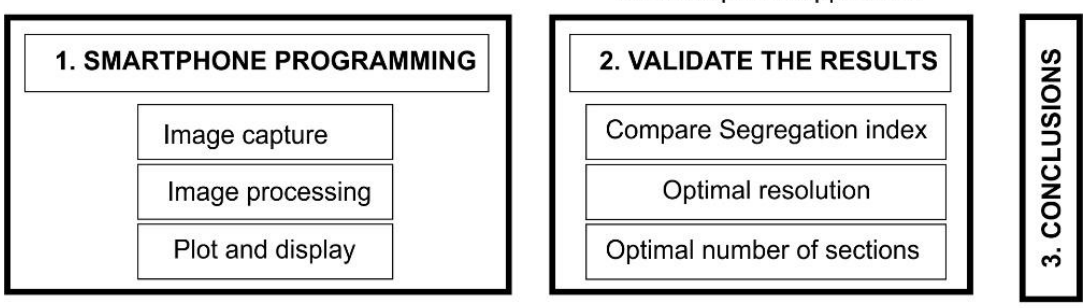

Segregation index programming: Ke et al. $\left(\mathrm{SI}_{\text {KeIA }}\right)$ and Solak et al. $\left(\mathrm{SI}_{\mathrm{IA}}\right)$

Figure 1. Scheme of the methodology followed. 


\subsection{Smartphone Programming}

Google provides developers with several tools to easily develop applications. The main tool used in this work was Android Studio based on InteliJ IDEA, which has several properties that made this environment useful for this project:

- $\quad$ an Android device emulator for testing;

- the ability to apply changes and test without stopping the execution;

- $\quad$ extensive debugging and testing tools.

In addition to Android Studio, a series of Android libraries were included to provide several functionalities for easily development of the application.

The Catalano framework [34] was used for processing the images captured with the smartphone, which includes tools for scientific computing for Java and Android. The library used in this project was an image processing library that has a series of image filters to achieve better binarization. For cropping the captured images, the Android Image Cropper library was used, which provide a visual method to crop an image prior to analysing the image that is optimized for the camera and the gallery of smartphones [35]. Finally, the AnyChart [36] library was used to plot, display, and manipulate graphs in real time with the results obtained after the analysis.

The interface design was done with the Justinmind tool [37], which facilitates the design of the mock-ups of the different screens that the application will have. This desktop application was specially designed for prototyping web pages and mobile applications. It has design tools that represent mobile application components and can be used to create the screen flow of the application.

\subsection{Methods for Measuring the Segregation through Image Analysis in Concretes}

There are several methods for measuring or identifying the segregation in concretes using image analysis techniques [22-25]. In this research, two different methods were selected based on studies that have been carried out by the authors. The two indexes obtained are described below.

Ke et al. proposed a procedure for determining the segregation index $\left(\mathrm{SI}_{\mathrm{Ke}}\right)$ of concretes $[28,38]$ with the ratio of densities measured in the same specimen (of the top section$\rho_{\text {top }}$ - and the bottom section- $\rho_{\text {bottom }}$ ) as can be seen in Equation (1).

$$
\mathrm{SI}_{\mathrm{Ke}}=\rho_{\mathrm{top}} / \rho_{\text {bottom }}
$$

The segregation index can be obtained with this method experimentally $\left(\mathrm{SI}_{\mathrm{Ke}}\right)$ or by using image analysis techniques ( $\mathrm{SI}_{\mathrm{Ke}} \mathrm{IA}$ ) [26]. It is necessary to determine the value of top and bottom densities. If $\mathrm{SI}_{\mathrm{Ke}}=1$, the specimen is considered to be in a condition of uniformity. For this method, the materials characterization is necessary because it is based on the density of the concrete produced (LWA and mortar density).

For determining the segregation index $\left(\mathrm{SI}_{\mathrm{IA}}\right)$, as suggested by Solak et al. [26], the cut cylinder concrete specimen should be photographed. The image of the sections are analysed using image analysis techniques determining black and white matrices [26,39]. In this method, the characterization of the materials for producing LWAC is not mandatory. The range of values of the $\mathrm{SI}_{\mathrm{IA}}$ varies from $0 \%$ (totally homogenous specimen) to $100 \%$ (totally segregated concrete where the aggregates are concentrated in the top of the specimen).

\subsection{Algorithm Design}

Solak's algorithm [26] is represented in Figure 2, and it proposes going through the image in two passes: (i) to calculate the global aggregate index (GAI) and (ii) another pass through each section of the sample, which is equivalent to going through the entire image again. 


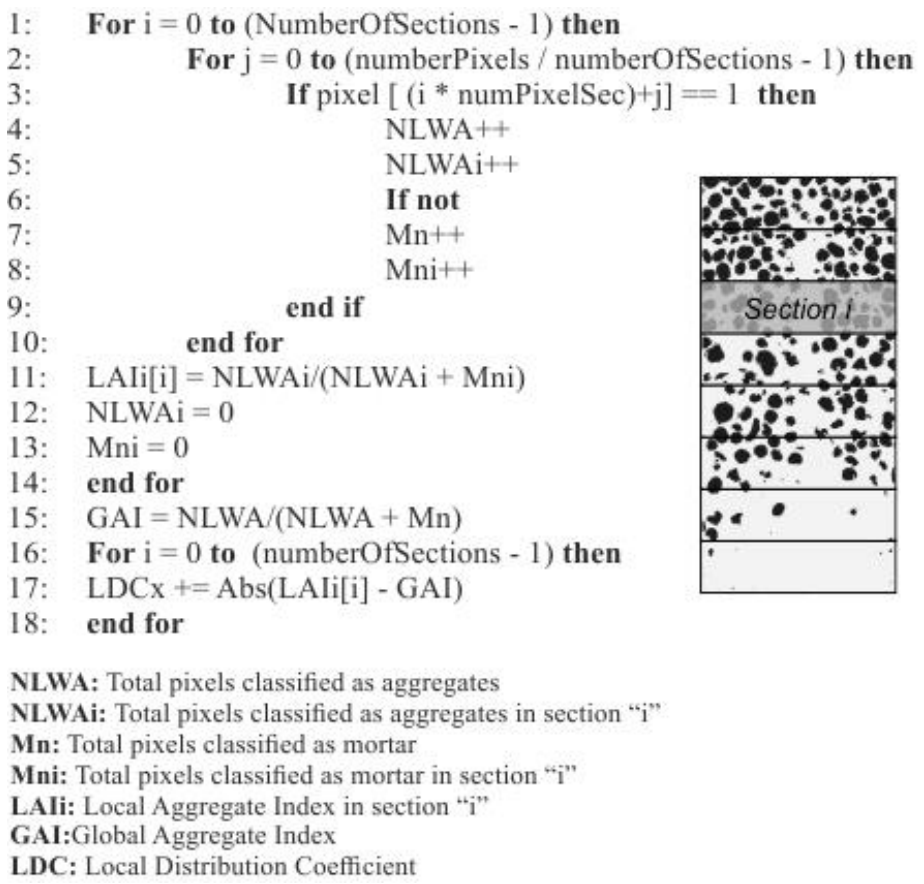

NLWA: Total pixels classified as aggregates

NLWAi: Total pixels classified as aggregates in section " $i$ "

Mn: Total pixels classified as mortar

Mni: Total pixels classified as mortar in section "i"

LAIi: Local Aggregate Index in section "i"

GAI:Global Aggregate Index

LDC: Local Distribution Coefficient

Figure 2. Algorithm of Solak et al.'s methodology [26].

To reduce the computation time, the code was designed to go through the entire image once. This corresponds to the first loop of the code, which goes through the image counting the total number of aggregate (black pixels) or cement mortar (white pixels) of each section and the entire sample.

Once the pixel count was obtained, it was stored in a data structure that has as many elements as the sample is divided into sections. With these numbers, the local aggregate index in each section (LAIi) parameter was calculated.

Subsequently, the positions of the data structure that contained the LAI values for each section were traversed, and their average was calculated but not before calculating the absolute value according to Equation (2).

$$
\mathrm{LAI}_{\mathrm{i}}-\mathrm{GAI}
$$

Finally, the SI segregation index was obtained by applying the last operation of the process. It can be seen that this algorithm tries to optimize the number of operations performed and the number of times the entire image is traversed, thus complying with the non-functional requirement of the application performance.

\section{Results and Discussion}

\subsection{Application Design and Programming}

The objective of the application is to apply the image analysis algorithm proposed by Ke et al. [28] and Solak et al. [26] and display the results. Since it is intended to be handled by people not specialized in computer applications, it must be very user-friendly, fast, and easy to use.

The application should allow the user: (a) to take a photograph of a concrete sample with the mobile phone; (b) process that image with the algorithm; and (c) display results of the segregation index of the concrete analysed.

All calculations are performed on the device itself, and no Internet connection is required, so that if it is being used on the job site in an area with a poor connection, there will be no problem. The images are stored in a Room database indicating the date and the segregation index. 
Figure 3 shows the functional blocks of the application and the interactions between them. The application has an interface, which is the user's access point to the functionalities of the application. This module communicates to the image processing component, which must analyse the image collected with the camera device. Once the task is completed, the data persistence component stores the results obtained.

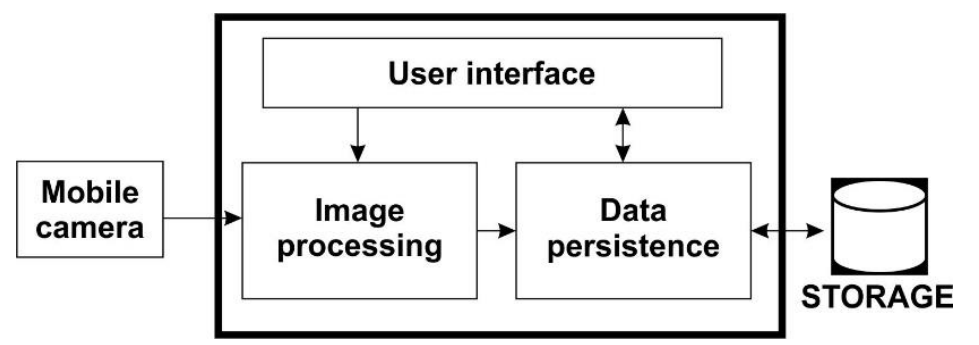

Figure 3. Functional blocks of the application and the interactions between them.

The data persistence module is responsible for storing the data in memory for later reading and observation by the user. The project was created in Android Studio (Figure 4a). It has an on-screen button to start a new analysis, a side navigation menu with the list of previous analyses, a tips screen, and another screen with information about the application.

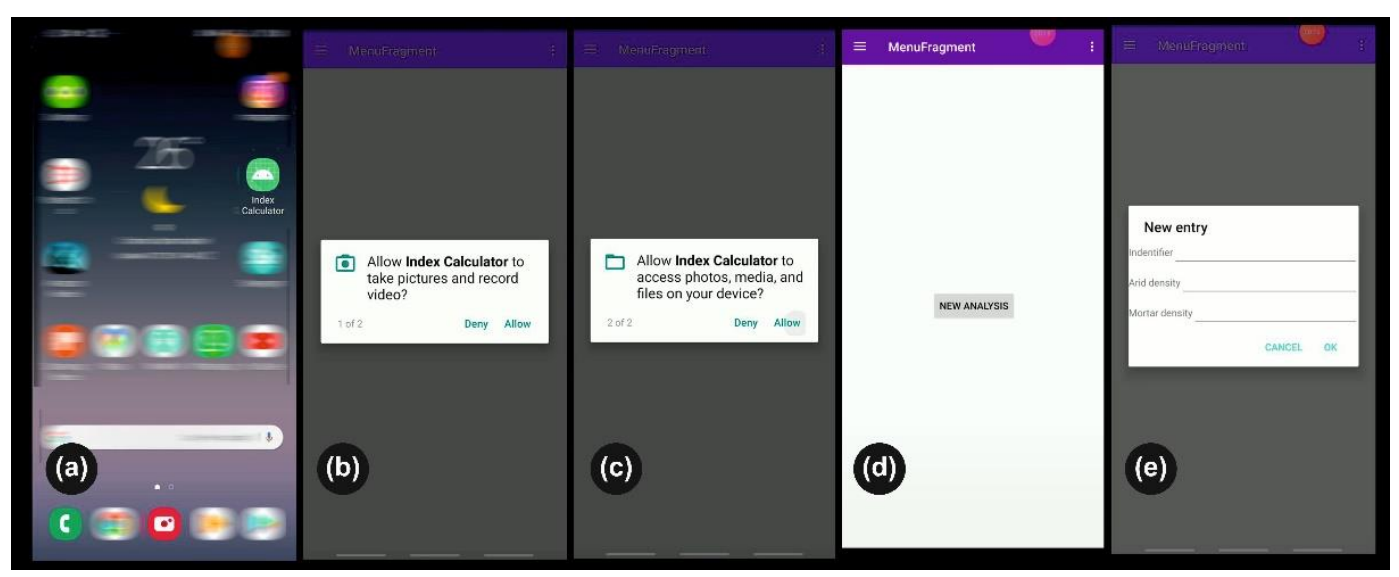

Figure 4. Screenshots of the mobile application: (a) the icon of the application; (b) permission to take pictures and record video; (c) permission to access the application to photo gallery; (d) start the analysis; (e) and data entry (identification of the sample and density of the aggregate and mortar for obtaining $\left.\mathrm{SI}_{\mathrm{Ke}} \mathrm{IA}\right)$.

The implementation of the different screens of the application is done by creating a fragment for each one. The components of the fragment, in addition to the class itself, are a viewModel, which is responsible for storing all the data pertaining to the screen being displayed. A viewModelFactory must also be created for each of the models. Finally, an XML file is created where the visual interface is defined, such as text boxes, buttons, and image position.

Inside the fragment there is a new analysis button (Figure $4 \mathrm{~d}$ ), which starts the analysis process of an image. When this button is clicked, a popup opens with three text fields to enter basic information for each sample (Figure $4 \mathrm{e}$ ).

Once all the fields are filled with the identification of the sample and the densities of the LWA and the mortar (Figure 5a), the user clicks on next, and another popup is displayed where the user selects whether the sample image will be captured (using the camera to take a photograph or selected from a picture from the gallery of the phone). When the image is selected, it needs to be cropped to adjust into the area of analysis (Figure 5b). This photograph, according to the image analysis procedure described in [26], is binarized using two filters, Bemsen and Bradley (Figure 5c), and the user selects the image that better 
represents the sample. Finally, the results are displayed in the last screen including the initial data and the results of the $\mathrm{SI}_{\mathrm{Ke} \mathrm{IA}}$ and $\mathrm{SI}_{\mathrm{IA}}$ (Figure $5 \mathrm{~d}$ ).

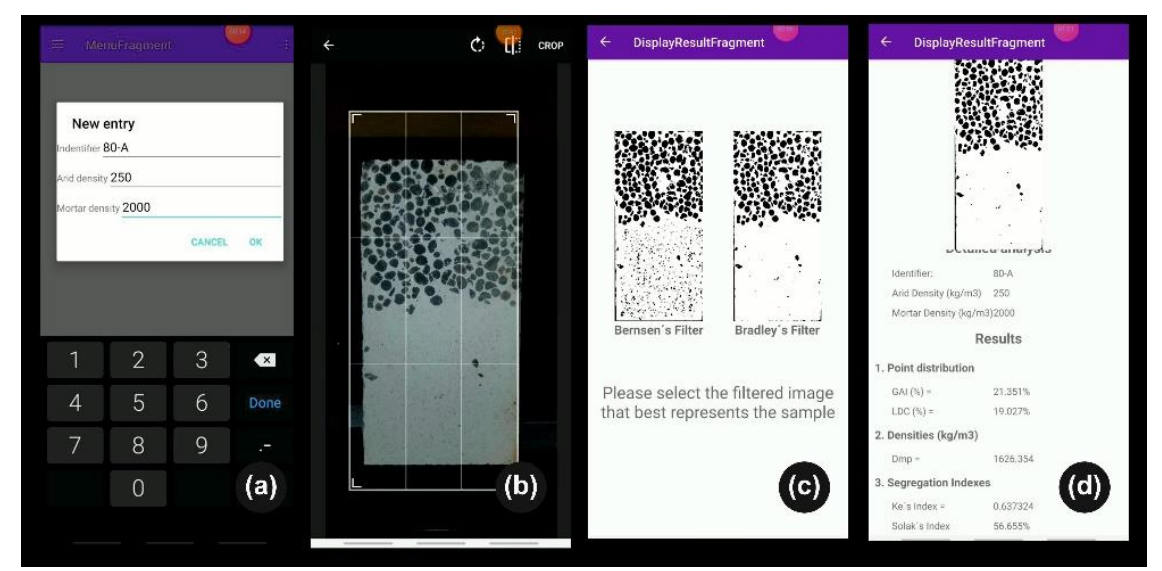

Figure 5. Screenshots of the mobile application: (a) identification of the sample and the LWA and mortar density; (b) picture of the sample ready to be cropped by the application; (c) options for selecting the filter that better represents the concrete sample; and (d) results.

\subsection{Main Parameters for the Mobile Application}

\subsubsection{Number of Sections}

As explained in Section 2.2., to obtain $\mathrm{SI}_{\mathrm{KeIA}}$, it is necessary to know the densities of the LWA and the mortar. The calculation is made by dividing the specimen into four sections and is calculated according to the Equation (1).

However, for the calculation of the $\mathrm{SI}_{\mathrm{IA}}$, the specimen is divided into "n sections". A larger number of sections increases the accuracy of the calculated index but consumes a significant amount of resources.

Figure 6 shows the results of SI IA applied from $n=2$ to $n=700$ sections in three LWAC manufactured with LWA Arlita Leca and designed with a theorical density of $1700 \mathrm{~kg} / \mathrm{m}^{3}$ (according to the Fanjul method [40]). This concrete was compacted varying the time of compaction (no vibration and 40 and $80 \mathrm{~s}$ ) to cause different LWA internal distributions. As can be seen, the $\mathrm{SI}_{\mathrm{IA}}$ results were constant from 250 sections; therefore, this was used as the number of sections chosen for the algorithm.
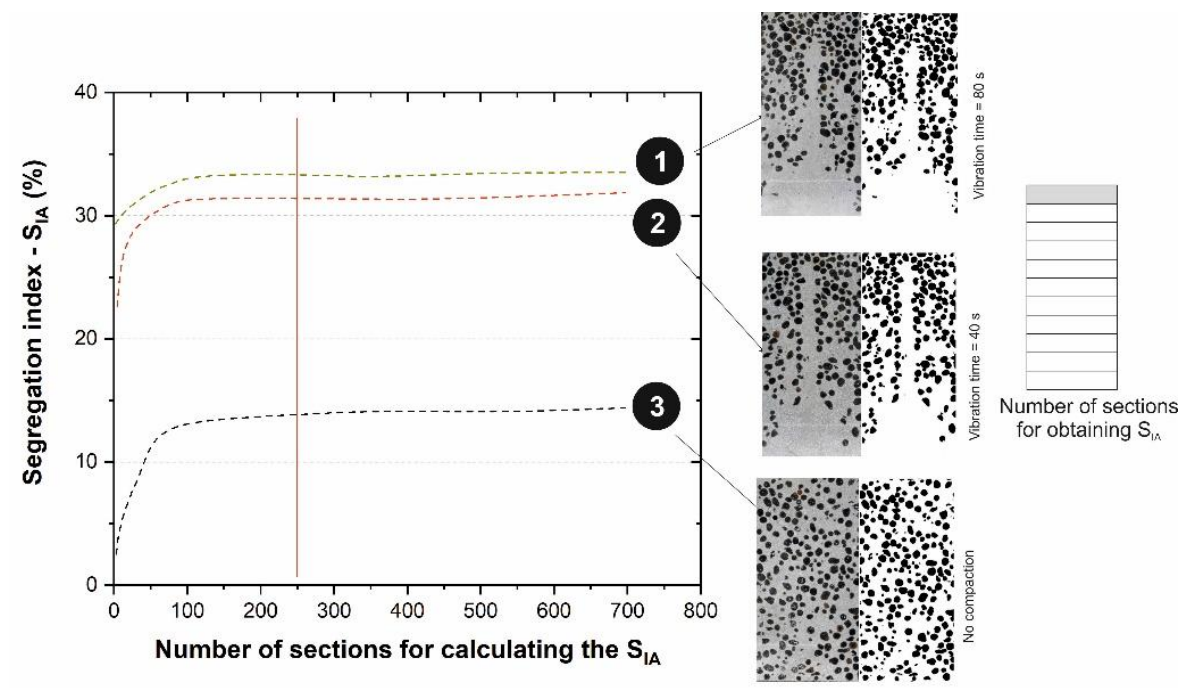

Figure 6. Variation of the segregation index with the number of sections selected for obtaining the value of $\mathrm{SI}_{\mathrm{IA}}$. 


\subsubsection{Photography Resolution}

To optimize the process of image analysis, the images could be with lower resolution than the original. It is convenient to make a reduction in the image resolution because the results were very similar, and the calculation time was considerably reduced. To determine the lower image resolutions to use in the analysis that do not affect the result, the $\mathrm{SI}_{\mathrm{IA}}$ of the previous concrete was calculated with 10 different resolutions (Figure 7). This process was repeated for three samples with different vibration times. As can be seen in Figure 7, the results of the $\mathrm{SI}_{\mathrm{IA}}$ calculation with different resolutions in this set of images remained constant up to $700 \times 325$ pixels; at that point, the results begin to vary considerably. Those results are in accordance with the resolution value used in several previously published works $[26,32,41]$.

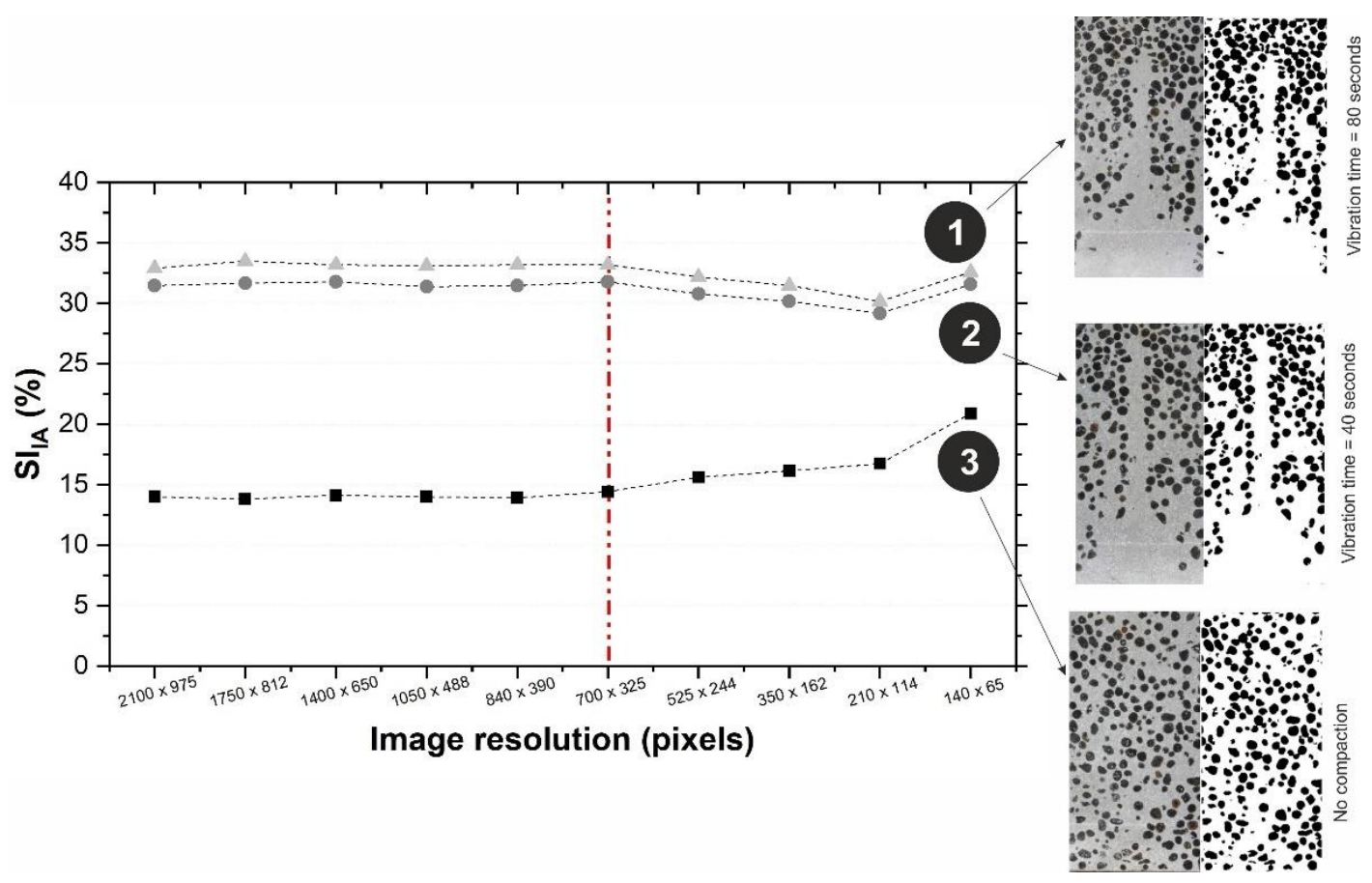

Figure 7. Variation of the segregation index with the resolution of the photography.

\subsection{Validation}

With the number of sections and resolution selected, the next step is to validate the values obtained in the mobile application. The photographs used for validation were those used for the research published in [10]. In this research, $\mathrm{SI}_{\mathrm{Ke}}$ was calculated according to Equation (1) and is represented in Figure 8 as SI $\mathrm{SI}_{\mathrm{Ke}}$ (experimental). In this research, $\mathrm{SI}_{\mathrm{Ke}} \mathrm{IA}$ was obtained by (a) ImageJ software and (b) the mobile application developed. 


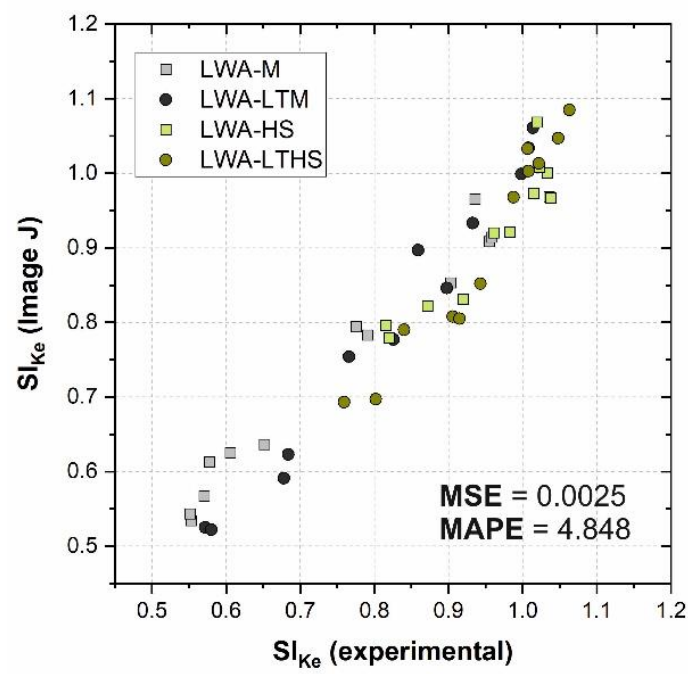

(a)

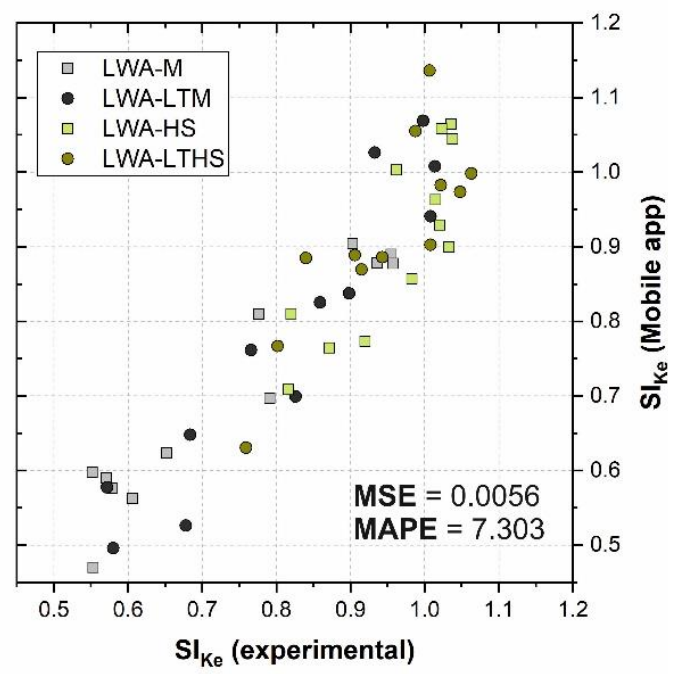

(b)

Figure 8. Segregation index obtained according Ke et al.'s methodology (densities of the samples) compared with the value obtained using (a) image analysis through Image J software and (b) obtained through mobile application developed.

The mean squared error (MSE) according to Equation (3) and the mean absolute percentage error (MAPE) according to the Equation (4) were used to evaluate the accuracy of the results taking as valid the measured value obtained experimentally $\left(\mathrm{SI}_{\mathrm{Ke}}\right)$.

$$
\begin{gathered}
M S E=\frac{\sum_{i=1}^{n}\left(R_{m i}-R_{c i}\right)^{2}}{n} \\
M A P E=\frac{\sum_{i=1}^{n}\left|R_{m i}-R_{c i}\right|^{2}}{n}
\end{gathered}
$$

Lower values of MSE and MAPE indicate better accuracy of the method used. As can be seen in Figure 8, the lower values were found in the images analysed by ImageJ software. However, the accuracy of the application was also significantly good because MSE and MAPE were low (the average difference between the value obtained by the mobile application and the result obtained experimentally was lower than $7.3 \%$ ).

Another analysis [32] was carried out to validate the data obtained by the mobile application and compared the dry density of the concrete obtained using image analysis by ImageJ of the LWAC section; it used the original images. The density parameters introduced in the mobile application (Figures $4 \mathrm{e}$ and $5 \mathrm{a}$ ) were $269 \mathrm{~kg} / \mathrm{m}^{3}$ for the aggregate and $2022 \mathrm{~kg} / \mathrm{m}^{3}$ for the mortar matrix, and the filters implemented in the application were applied.

As can be seen in Figure 9, the results obtained using image analysis with ImageJ and using the mobile application did not match perfectly due to the automatic filtering used by the application or because the crop of the image could be different. However, it can be observed that the difference was not very pronounced, and it can be affirmed that the agility in obtaining results is more important than their accuracy. 


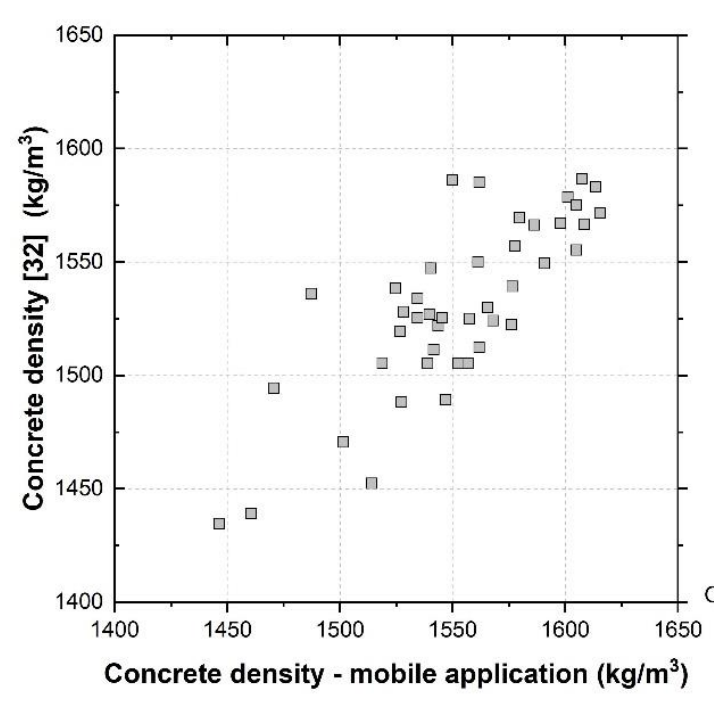

(a)

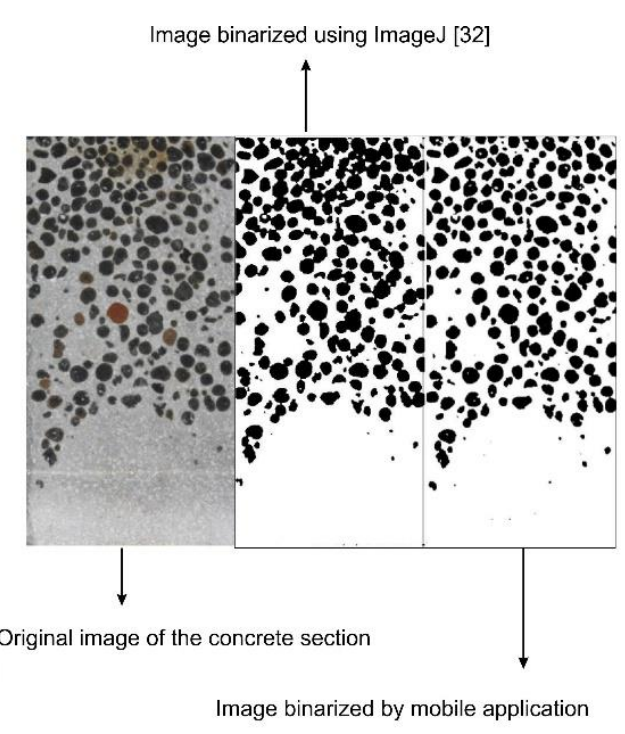

(b)

Figure 9. (a) Concrete density of different samples obtained through image analysis (published in [32] and obtained by mobile application). (b) An example of the original photograph and the binarization done in the research published in [32] and using the mobile phone application.

Consequently, it is concluded that the application is suitable to carry out this type of analysis. To make the application, a detailed analysis was implemented (Figure 10). As can be seen in Figure 10, the "detailed analysis" offered by the application incorporated all the data that may be of interest to researchers who analyse the phenomenon of segregation in concretes. It includes values such as the density of the concrete, the density in four different sections, the black pixels (aggregates) in the sections, and even density profile plots, where you can visually see both the density in 250 sections and the variation of the sections' density with regard to the average density of the concrete. To finalise the detailed analysis of the mobile application, the application allows the analysis to be exported into a comma-separated values (CSV) file, which can be easily sent by e-mail.

The finished product was tested by the researchers of this work on real samples to verify that the application met the expected quality standards and that it satisfised the requirements set by the application design. The main advantages of the mobile application are the speed of image capture and the cropping and analysis compared to the traditional methodology using a professional camera and computer image processing software. This allows considerable time savings when a large number of images need to be processed. However, image processing control is lost, and the image can be binarized with only two filters, which greatly simplifies the process but may lead to overestimating or underestimating the black and white matrices.

The Android package (APK) to install on the mobile phone can be downloaded from the Supplementary Material (APK S1). A demonstration about the use of the application can also be found in the Supplementary Material (Video S1). 


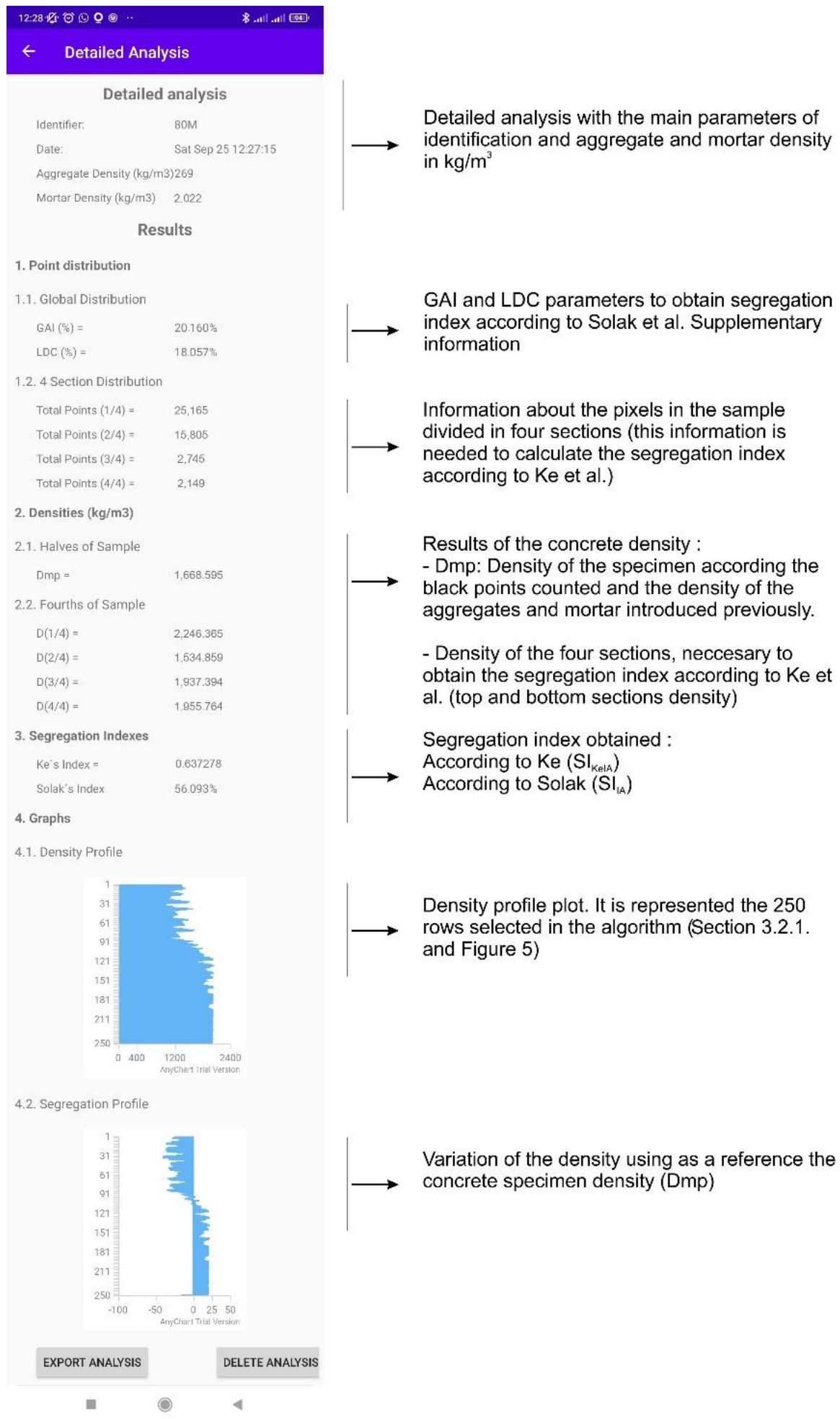

Figure 10. Detailed analysis of the concrete specimen extracted from the mobile application.

\section{Conclusions}

This research and proposed application for mobile users show the advantage of using this application to easily apply the image analysis techniques to obtain the segregation index of lightweight concrete. The main conclusions after validating the results offered by the mobile application are:

- Users can use the application with camera phones and obtain, directly, the main parameters to analyse the segregation in concretes sections. 
- A low-cost, simple method for determination of segregation through digital imaging was developed and validated.

Supplementary Materials: The following are available online at https://www.mdpi.com/article/ 10.3390/su132212564/s1, APK S1: Segregation index APK to install in the mobile phone, Video S1: Demonstration of the mobile application usability.

Author Contributions: Conceptualization, A.J.T.-A., P.C.-R., R.S.-C. and A.M.S.; data curation, A.J.T.-A. and R.S.-C.; formal analysis, A.J.T.-A., P.C.-R. and D.G.F.; funding acquisition, A.J.T.-A.; investigation, A.J.T.-A., P.C.-R., R.S.-C., A.M.S. and D.G.F.; methodology, A.J.T.-A., R.S.-C., A.M.S. and D.G.F.; project administration, A.J.T.-A. and P.C.-R.; resources, P.C.-R.; supervision, P.C.-R., R.S.-C. and A.M.S.; writing—original draft, D.G.F.; writing—review \& editing, A.J.T.-A., P.C.-R., R.S.-C. and A.M.S. All authors have read and agreed to the published version of the manuscript.

Funding: This research was funded by the University of Alicante, GRE13-03, and VIGROB-256.

Institutional Review Board Statement: Not applicable.

Informed Consent Statement: Not applicable.

Data Availability Statement: Not applicable.

Acknowledgments: The authors wish to express their gratitude to the Ph.D. program in Materials,

Conflicts of Interest: The authors declare no conflict of interest. The funders had no role in the design of the study; in the collection, analyses, or interpretation of data; in the writing of the manuscript; or in the decision to publish the results.

\section{References}

1. Dabbaghi, F.; Tanhadoust, A.; Nehdi, M.L.; Nasrollahpour, S.; Dehestani, M.; Yousefpour, H. Life cycle assessment multi-objective optimization and deep belief network model for sustainable lightweight aggregate concrete. J. Clean. Prod. 2021, 318, 128554. [CrossRef]

2. Pla, C.; Tenza-Abril, A.J.; Valdes-Abellan, J.; Benavente, D. Influence of microstructure on fluid transport and mechanical properties in structural concrete produced with lightweight clay aggregates. Constr. Build. Mater. 2018, 171, 388-396. [CrossRef]

3. Rossignolo, J.A.; Agnesini, M.V.C.; Morais, J.A. Properties of high-performance LWAC for precast structures with Brazilian lightweight aggregates. Cem. Concr. Compos. 2003, 25, 77-82. [CrossRef]

4. Hwang, C.L.; Hung, M.F. Durability design and performance of self-consolidating lightweight concrete. Constr. Build. Mater. 2005, 19, 619-626. [CrossRef]

5. Strzałkowski, J.; Sikora, P.; Chung, S.Y.; Abd Elrahman, M. Thermal performance of building envelopes with structural layers of the same density: Lightweight aggregate concrete versus foamed concrete. Build. Environ. 2021, 196, 107799. [CrossRef]

6. Real, S.; Gomes, M.G.; Moret Rodrigues, A.; Bogas, J.A. Contribution of structural lightweight aggregate concrete to the reduction of thermal bridging effect in buildings. Constr. Build. Mater. 2016, 121, 460-470. [CrossRef]

7. Ting, T.Z.H.; Rahman, M.E.; Lau, H.H. Sustainable lightweight self-compacting concrete using oil palm shell and fly ash. Constr. Build. Mater. 2020, 264, 120590. [CrossRef]

8. Bogas, J.A.; de Brito, J.; Figueiredo, J.M. Mechanical characterization of concrete produced with recycled lightweight expanded clay aggregate concrete. J. Clean. Prod. 2015, 89, 187-195. [CrossRef]

9. Yu, Q.L.; Spiesz, P.; Brouwers, H.J.H. Ultra-lightweight concrete: Conceptual design and performance evaluation. Cem. Concr. Compos. 2015, 61, 18-28. [CrossRef]

10. Tenza-Abril, A.J.; Benavente, D.; Pla, C.; Baeza-Brotons, F.; Valdes-Abellan, J.; Solak, A.M. Statistical and experimental study for determining the influence of the segregation phenomenon on physical and mechanical properties of lightweight concrete. Constr. Build. Mater. 2020, 238, 117642. [CrossRef]

11. Solak, A.M.; Tenza-Abril, A.J.; Baeza-Brotons, F.; Garcia-Vera, V.E.; Lanzón, M. Experimental procedures for determining the level of segregation of Lightweight Aggregate Concretes. In Proceedings of the SynerCrete'18: Interdisciplinary Approaches for Cement-based Materials and Structural Concrete: Synergizing Expertise and Bridging Scales of Space and Time Funchal, Madeira Island, Portugal, 24-26 October 2018.

12. Stock, A.F.; Hannant, D.J.; Williams, R.I.T.; Hannantt, D.J.; Williams, R.I.T. The effect of aggregate concentration upon the strength and modulus of elasticity of concrete. Mag. Concr. Res. 1979, 31, 225-234. [CrossRef]

13. Solak, A.M.; Tenza-Abril, A.J.; Saval, J.M.; García-Vera, V.E. Effects of multiple supplementary cementitious materials on workability and segregation resistance of lightweight aggregate concrete. Sustainability 2018, 10, 4304. [CrossRef]

14. Panesar, D.K.; Shindman, B. The effect of segregation on transport and durability properties of self consolidating concrete. Cem. Concr. Res. 2012, 42, 252-264. [CrossRef] 
15. Navarrete, I.; Lopez, M. Estimating the segregation of concrete based on mixture design and vibratory energy. Constr. Build. Mater. 2016, 122, 384-390. [CrossRef]

16. Tenza-Abril, A.J.; Villacampa, Y.; Solak, A.M.M.; Baeza-Brotons, F. Prediction and sensitivity analysis of compressive strength in segregated lightweight concrete based on artificial neural network using ultrasonic pulse velocity. Constr. Build. Mater. 2018, 189, 1173-1183. [CrossRef]

17. Yang, Y.S.; Wu, C.L.; Hsu, T.T.C.; Yang, H.C.; Lu, H.J.; Chang, C.C. Image analysis method for crack distribution and width estimation for reinforced concrete structures. Autom. Constr. 2018, 91, 120-132. [CrossRef]

18. Hutchinson, T.C.; Chen, Z. Improved Image Analysis for Evaluating Concrete Damage. J. Comput. Civ. Eng. 2006, 20, 210-216. [CrossRef]

19. Naser, M.Z. Autonomous Fire Resistance Evaluation. J. Struct. Eng. 2020, 146, 04020103. [CrossRef]

20. Liu, B.; Yang, T. Image analysis for detection of bugholes on concrete surface. Constr. Build. Mater. 2017, 137, 432-440. [CrossRef]

21. Moreno Juez, J.; Artoni, R.; Cazacliu, B. Monitoring of concrete mixing evolution using image analysis. Powder Technol. 2017, 305, 477-487. [CrossRef]

22. Pan, J.; Gao, X.; Ye, H. Influence of Rheological Behavior of Mortar Matrix on Fresh Concrete Segregation and Bleeding. Iran. J. Sci. Technol. Trans. Civ. Eng. 2021, 45, 1281-1295. [CrossRef]

23. Roussel, N. A theoretical frame to study stability of fresh concrete. Mater. Struct. Constr. 2006, 39, 81-91. [CrossRef]

24. Barbosa, F.S.; Farage, M.C.R.; Beaucour, A.L.; Ortola, S. Evaluation of aggregate gradation in lightweight concrete via image processing. Constr. Build. Mater. 2012, 29,7-11. [CrossRef]

25. Barbosa, F.S.; Beaucour, A.L.; Farage, M.C.R.; Ortola, S. Image processing applied to the analysis of segregation in lightweight aggregate concretes. Constr. Build. Mater. 2011, 25, 3375-3381. [CrossRef]

26. Solak, A.M.; Tenza-Abril, A.J.; Baeza-Brotons, F.; Benavente, D. Proposing a new method based on image analysis to estimate the segregation index of lightweight aggregate concretes. Materials 2019, 12, 3642. [CrossRef]

27. Han, J.; Wang, K.; Wang, X.; Monteiro, P.J.M. 2D image analysis method for evaluating coarse aggregate characteristic and distribution in concrete. Constr. Build. Mater. 2016, 127, 30-42. [CrossRef]

28. Ke, Y. Caractérisation du Comportement Mécanique des Bétons de Granulats Légers: Expérience et Modélisation. Ph.D. Thesis, Université de Cergy-Pontoise, Paris, France, 2008.

29. Han, J.; Yan, P. Influence of segregation on the permeability of self-consolidating concrete. Constr. Build. Mater. 2021, $269,121277$. [CrossRef]

30. Rajendran, R.; Rajendiran, J. Image Analysis Using Smartphones for Medical Applications: A Survey. In Intelligent Pervasive Computing Systems for Smarter Healthcare; Wiley: Hoboken, NJ, USA, 2019; pp. 275-290. ISBN 9781119439004.

31. Thabet, R.; Mahmoudi, R.; Bedoui, M.H. Image processing on mobile devices: An overview. In Proceedings of the International Image Processing, Applications and Systems Conference, IPAS 2014; Institute of Electrical and Electronics Engineers Inc., Hammamet, Tunisia, 5-7 November 2014.

32. Solak, A.M. El fenómeno de la segregación en hormigones ligeros. Análisis mediante procesamiento de imágenes y estudio ultrasónico. Master's Thesis, Universidad de Alicante, Alicante, Spain, 2017.

33. Solak, A.M.; Tenza-Abril, A.J.; Baeza-Brotons, F. Image analysis applications for the study of segregation in lightweight concretes. Int. J. Comput. Methods Exp. Meas. 2018, 6, 835-846. [CrossRef]

34. Catalano, M.D. Catalano Framework 1.6.1.1. Available online: https://github.com/DiegoCatalano/Catalano-Framework/ releases/tag/v1.6.1.1-libs (accessed on 30 July 2020).

35. ArthurHub Android-Image-Cropper 2.8.0. Available online: https://github.com/ArthurHub/Android-Image-Cropper (accessed on 30 July 2020).

36. ArsenyMalkov AnyChart-Android. Available online: https://github.com/AnyChart/AnyChart-Android (accessed on 30 July 2020).

37. Prototype Web and Mobile Apps. Available online: https://www.justinmind.com/ (accessed on 30 July 2020).

38. Ke, Y.; Beaucour, A.L.; Ortola, S.; Dumontet, H.; Cabrillac, R. Influence of volume fraction and characteristics of lightweight aggregates on the mechanical properties of concrete. Constr. Build. Mater. 2009, 23, 2821-2828. [CrossRef]

39. Solak, A.M.; Tenza-Abril, A.J.; García-Vera, V.E. Influence of the segregation phenomenon on structural efficiency of lightweight aggregate concretes. Materials 2020, 13, 5754. [CrossRef]

40. Fernández-Fanjul, A.; Tenza-Abril, A.J. Méthode Fanjul: Dosage pondéral des bétons légers et lourds. Journal du Bâtiment et des Travaux Publics 2012, 5, 32-50.

41. Solak, A.M.; Tenza-Abril, A.J.; Baeza-Brotons, F.; Fernández-Fanjul, A.; Brotons, F.B.; Fernandez-Fanjul, A. El fenómeno de la segregación en hormigones ligeros. Índice de Segregación y estudio ultrasónico. In Proceedings of the VII Congreso Internacional de Estructuras, A Coruña, Spain, 20-22 June 2017. 